\title{
Os complementos de lugar em latim clássico e latim vulgar: uma comparação
}

\author{
Maria Cristina Martins
}

Resumo: This paper compares the use of locatives in classical and vulgar latin. The classical or literary latin is exemplified by Cesar and Cicero, and the vulgar latin by the letters of an anonymous tiberian soldier and a letter of Rustius Barbarus, both of the II' century a.D. We show, on one hand, that the syntax of the traditional "questions of place" in classical language is very complex and specific. On the other hand, we show that in vulgar latin the syntax of locatives presents several differences comparing to the classical latin, mainly between the places ubi and quo.

Palavras-chave: locativos, latim clássico, latim vulgar, sintaxe comparativa, lingüística histórica, lingüística românica, filologia românica, línguas clássicas.

\section{Introdução}

"Latim clássico" é a norma literária, altamente estilizada, que compreende o período que vai de 81 a. C. a 14 d.C. Esta norma literária coexistia com o sermo urbanus ou usualis, língua coloquial das classes cultas, e com o sermo plebeius, que pode ser ainda subdividido em outras variedades, notadamente no sermo

Maria Cristina Martins é professora adjunta de língua e literatura latina no Instituto de Letras/ UFRGS. 
castrensis ou militaris (língua dos soldados), no sermo rusticus (língua regional), sermo peregrinus (língua dos estrangeiros).

"Latim vulgar" é o termo tradicionalmente usado para se referir ao latim ue mostra um conjunto de inovaçóes gramaticais que não seguem as normas que mostra um latim literío (clássico), e que pode ser tomado como o latim falado. Este a atim pertencia a uma pos literários.

As expressões de lugar em latim clássico correspondem (e respondem) aos (para onde) equa (poronde). quatro advérbios ubi (onde), unde (de onde), quo (para onde) equa (por onde). O uso específico de cada complemento em latim clássico está relacionado, em linhas gerais, ao fato desse complemento completar um verbo que tem a semantica de movimento ou completar o sentido de um verbo de natureza estáica.

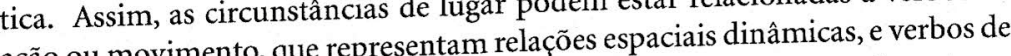
ação ou movimento, que representam relaçôs espaciais dinamicas, e verbos estado, que se referem ao estado das coisas e não à açao, ao acontecimento ou processo, cujas circunstâncias de lugar estão associadas a relações espaciais estáprocen há particularidades envolvidas em relação ao ticas. Dentro dessa divisáo geresentam noções semânticas seuso de preposições adequadas, pois estas representam de cima para baixo, de um cundárias, tais como a indicação de um movim

movimento com ou sem entrada no lugar etc.

Em latim vulgar, observa-se, em geral, um incremento no uso de preposições, tradicionalmente explicado pela busca de uma maior clareza de expressão, pela intensificação nas relações de complemento e também pela necessidade imposta pela perda da morfologia flexional de certos casos e a conseqüente conseqüentemente, houve ambiente para uma indistinção confusão entre eles. Consequentemente, houve vai". Na sintaxe das expressões de lugar, observam-se ainda outras transformações pelas quais a língua latina esava passando: a redução dos ditongos, a confusão entre os casos acusativo e tava passand ablativo, devido à queda do $-m$ nos exemplos, entre outras coisas.

\section{As expressões de lugar em latim clássico}

Como se disse acima, as questões de lugar em latim clássico respondem aos quatro advérbios de lugar: $u b i$, unde, quo, qua.

2.1. Lugar "onde" - locus "ubi"

O lugar onde (ubi) quase sempre vem expresso pelo ablativo (também chaOrganon, Porto Alegre, $\mathrm{n}^{\mathrm{n}}$ 44/45, janeiro-dezembro, 2008, p. 89-102 mado "ablativo-locativo") com as preposições in e $s u b$, sem a idéia de movimento, em oposição ao acusativo.

Cíc., Ver. 5, 27: coronam habere in capite. "ter uma coroa na cabeça." Cés., B.G. 1,21,1; hostes sub monte concedisse "os inimigos tinham se estabelecido ao pé de um monte."

$\mathrm{Na}$ expressão do lugar $u b i$ existem ainda resquícios do antigo caso locativo, quase sempre indicando topônimos. Os principais exemplos são com nomes de cidades e também de ilhas pequenas. Apresenta desinências em ae e $i$, que se confundem com o genitivo, para os nomes que pertencem à primeira e segunda declinação: Romae, Tarenti. Porém, se o nome é plural e da primeira ou segunda declinação, como Athenae, o lugar "onde" corresponde ao ablativo sem preposição: Athenis. Nas demais declinações, a desinência é igual ao ablativo, como por exemplo, Carthagine.

Existem ainda palavras isoladas no caso locativo que sobreviveram em latim clássico: domi "em casa", humi "na terra", ruri "no campo", duelli (= belli) "na guerra", militiae "no exército", uiciniae "na vizinhança."

Sum Romae, domi, ruri, humi. "Estou em Roma, em casa, no campo, no chão".

Observações sobre os complementos de lugar - casos especiais:

Quando as palavras domus e rus e ainda nomes de cidades vierem acompanhadas de uma determinação, sujeitam-se à regra geral, assim como o aposto de um nome de cidade:

Sum in ipsa Roma - "Estou na própria Roma"

Eo in urbem Romam "Vou para a cidade de Roma"

Eo in pulcherrimam domum "Vou para uma casa lindíssima"

Redeo Roma ex urbe nobili "Volto de Roma, nobre cidade"

Redeo ex amplissima domo "Volto de uma casa muito ampla"

Sum Corinthi, in oppido opportuno "Estou em Corinto, cidade bem situada"

A palavra domus, se for acompanhada de um pronome possessivo, de alienus ou de um genitivo, pode seguir ou não a regra geral:

Domi meae ou in domo mea- "Na minha casa"

Domi Caesaris ou in domo Caesaris "Na casa de César"

Eo domum meam ou in domum meam "Vou para minha casa"

Redeo domo mea ou e domo mea "Regresso/volto de minha casa"

Os poetas omitem muitas vezes as preposições com os complementos de lugar onde, de onde e para onde:

Celsa sedet arce Aeolus (Virgílio, Eneida, I, 56) "Eolo está sentado no seu trono"

Descendere caelo (Hor. C., 3,4,1) descer do céu

At nos ... sitientes ibimus Afros (Virg., B., 1, 64) "E nós iremos para a África ardente".

Organon, Porto Alegre, nº 44/45, janeiro-dezembro, 2008, p. 89-102 
2.2. Lugar "de onde" - lócus "unde"

lugar de onde (unde) em latim clássico é expresso pelo caso ablativo, que, $\mathrm{m}$ latim, engloba três antigos casos do indo-europeu: o ablativo propriamente dito, $o$ instrumental e o locativo.

out menciona a questão da perda dos casos como uma tendência geral no desenvolvimento das línguas indo-européias:

"Cette réduction du nombre (ou syncrétisme) de cas est un fait général du développement des langues indo-européennes. Outre ceux qui viennent d'être développement des langues indo do latim clássico], la flexion primitive avai mentionnés [a saber os casos do latim clássico], la fexion primitive avait encore l'instrumental et le locatif, qui subsistent en sanscrit, en lituanien, et dans les langues eslaves, mais qui en latin sont fondus avecl'ablatif proprement dit, avant l'epoque historique; seules quelques formes de locatif (belli, dometc) ont conservé un emploi distinct, du rest restreint. Le grec est alle encore plus loin dans cette voie, puisqu'il a perdu également l'ablatif, de sorte que les fonctions de ablatif proprement dit de l'instrumental et du locat

Responde à pergunta unde o ablatiuus casus, que é o ablativo propriamente dito, derivado do verbo auferre que significa "levar", "tirar", "tomar", etc, cuja função primordial é indicar o ponto de partida, mas também a extensão e a separação.

Ligam-se ao ablativo propriamente dito as preposições $a(b)$, de e $e(x)$.

- A ou $a b+$ ablativo

Expressa em geral o afastamento de um lugar, em oposição a $a d$. Mais espees um movimento onde a direção é a mesma, mas os sentidos são diferentes.

A designa um movimento que parte das cercanias de um lugar ou objeto, como em:

a signo Vortumni uenire (Cíc., Ver. I, 154): "vir (de perto) da estátua de Vertumno."

- Ex ou $e+$ ablativo

Caracteriza um movimento que parte de um lugar ou do próprio objeto: E castris erumpere (Cés., B.G. 3,5,3) "sair violentamente fora do acampamento."

$A b$ e ex opõem-se da mesma maneira que ad e in, como veremos adiante.

- De + ablativo

Caracteriza um movimento de cima para baixo, mas também proveniência Caracteriza um move em descendere "descender"), afastamento, tal como em A caelo ad terram, de terra ad sidera mundi (Lucr. 1,788): "do céu à terra, Organon, Porto Alegre, $\mathrm{n}^{\mathrm{e}} 44 / 45$, janeiro-dezembro, 2008, p. 89-102 da terra aos astros do mundo"

decidere de lecto (Plauto) "cair da cama."

(...) ut de finibus suis exirent (César, B.G.1,2,2) “... que saíssem de suas fronteiras."

Dentre as construções de ablativo preposicionado com $a b$, ex, de, a construção com de foi a mais resistente, por sua inicial consonântica, cobrindo as outras formas com $a b$ e ex. O testemunho das línguas românicas, onde apenas de sobreviveu, comprova esta preferência em latim vulgar.

Sendo o complemento um nome cidade ou ilha pequena, usa-se o ablativo sem preposição:

Caesar Roma profectus est "César partiu de Roma."

Seguem a regra dos nomes de cidades os substantivos humus, rus e domus, podendo-se a este último acrescentar o genitivo do possuidor ou um adjetivo, que indica o possuidor. Exemplos:

Humo se tollere. "Levantar-se do chão."

Rure venit. "Veio do campo."

Domo Ciceronis, domo mea venio. "Venho da casa de Cícero, da minha casa."

\subsection{Lugar "para onde" - lócus "quo"}

O lugar "para onde" (quo) se vai é construído com o acusativo (acusativo de movimento). Designa o termo sobre o qual se dirige o movimento e, se bem que usualmente venha acompanhado de preposição, quando o complemento é um nome de cidade ou ilha pequena este vai para o acusativo sem preposição:

Cíc. Nat. 3, 83: Nauigare Syracusas: "navegar para Siracusa."

Seguem essa regra os nomes de cidade e os substantivos rus e domus. Exemplos:

Rus, domum ibo: "Irei para o campo, para casa."

Eo domum Pompei, domum meam, alienam. "Vou à casa de Pompeu, à minha casa, à casa alheia."

Usa-se o acusativo preposicionado - com as preposições in ou ad - quando se quer indicar se o movimento é com entrada no lugar (in + acusativo), ou se o movimento é até um lugar (às cercanias de um lugar) ( $a d+$ acusativo). Exemplos:

Cés. B.G. 5, 50, 4: equitatus ad castra accedit: "a cavalaria se aproximou do acampamento."

Cés. B.G. 1,10: (Caesar) ipse in Italiam magnis itineribus contendit:

"(César) ele próprio se dirige à Itália com marchas forçadas."

Organon, Porto Alegre, $\mathrm{n}^{\mathrm{a}} 44 / 45$, janeiro-dezembro, 2008, p. 89-102 
Nas cartas que contêm vulgarismos, observam-se ainda os diversos casos morfológicos, mas já aparecem confusões entre eles, pela perda das consoantes finais e pelo enfraquecimento do timbre vocálico.

Uma das razões pelas quais as chamadas "questões de lugar" confundiramse e mudaram a regência em latim vulgar, deve-se à queda do $-m$ final do acusativo. Por serem os únicos casos latinos regidos por preposição, desde cedo eram usados um pelo outro. Nessa disputa o acusativo foi o vencedor. Além disso, nas questóes de lugar, temos ainda sutilezas semânticas, envolvidas nos diversos complementos, que se traduzem pelo emprego dos diferentes casos e preposições. Conseqüência desta confusão está na hesitação entre as questões de lugar $u b i$ (onde) e quo (para onde).

\subsection{Confusão entre os Iugares ubi (onde) e quo (para onde)}

(Carta 1, linha 4-5) Si aequm tempus esset se exiturum Alexandrie s(i)lui( $(t)$. "se fizesse tempo bom, ele não disse que iria para Alexandria."

A sintaxe clássica pediria Alexandriam.

O caso locativo é usado diversas vezes na carta 1 , com a palavra Alexandriae, escrita sem o ditongo final, ou seja, Alexandrie. O locativo é uma sobrevivência do indo-europeu e seu uso é muito restrito em latim. Quando o soldado usa Alexandrie como complemento de um verbo de movimento, tal como na frase acima, cujo verbo é exire, na verdade deveria usar o acusativo, pois, conforme a sintaxe clássica, ele está respondendo a uma questão quo ("para onde"). Ou seja, em vez de Alexandrie, deveríamos ter Alexandriam, porque é complemento do verbo exire, que dentre tantas acepções, nesta ocorrência toma o sentido de "ir para", portanto um verbo de movimento. Assim, pois, este é um dos exemplos de confusão entre os lugares "onde se está" e "para onde se vai."

(Carta 1 , linha 8) ... et factum est illi venire Alexandrie con tirones. ".. e aconteceu de ele vir a Alexandria com os recrutas."

Venire, com sentido de "vir" em latim clássico é um verbo de movimento que responde à pergunta unde ("de onde"). Demanda um tipo de complemento que chamaremos de "básico": o lugar de origem, lugar de onde se vem, que em latim clássico é usado com o ablativo, com ou sem preposição. Poderia aparecer em seguida um complemento secundário, o lugar para onde se vai, em acusativo, com ou sem preposição (quando o complemento é um nome de cidade, etc.). Um exemplo típico em latim clássico é Uenire Delum Athenis "Vir de Atenas a Delos" (Cíc. Att. 5,12). Uenire no sentido de "chegar" é empregado mais comumente em latim clássico com in + acusativo e ad + acusativo, havendo determinaç̃es secundárias sobre o movimento conforme a preposição usada: "entrar no lugar" versus "não entrar lugar."

Organon, Porto Alegre, $n^{0} 44 / 45$, janeiro-dezembro, 2008, p. 89-102 
exemplo de uso do que, aparentemente, é o advérbio $i b i$ :

(carta 1, linhas 3-4) Ego tamen inc ebinde collexi paucum aes ed ibi ad

Nesta ocorrência, cujo sentido é de "vir, chegar", teríamos, conforme as grarios do latim, venire Alexandriam, conforme o teste Cícero, que vimos mais acima.

Observem-se ainda os usos do verbo venire no período abaixo:

(Carta 1, linha 11) Spec(t)

et deduco te usque ad nave.

"esperemos até que ele chegue então e vou contigo para Alexandritivo,

A primeira ocorrência de venire tem sentido de "chegar, locativo deveríamos mas a seguinte é claramente de "ir." Novamente, em vez de locativo deveria a um ter um acusativo de movimento. Alexandrie é um locativo, que responde "para lugar "onde" e está no lugar de um acusativo, que responde a um lugar "para onde". Com efeito, as nuances semânticas que diferenciam um movimento "daqui para lá" e "de lá para cá", tanto nos verbos quanto nas preposiçó conforam fáceis de serem detectadas pela população em geral. Ainda hoje se confundem no português popular ir e vir, levar e trazer.

A hesitação no emprego de venire, ora por vir, ora por ir, pode ser vista nos exemplos abaixo:

venirecon rebus meis Alexandrie que (eu) possa ir a Alexandria com "Dê-me um pouco

as minhas coisas."

(Carta 1, linha 15) Veni, dicet, Alexandrie et dabo

"Vem, disse ele, a Alexandria e te darei (...)". vendidi( $t)$ lentiamina $(u) t$ (Carta 1, linha 17)

veniam Alexandrie.

"Minha mãe, năo

viesse a Alexandria."

Tal como vimos acontecer anteriormente, essas três últimas ocorindica um demandariam o acusativo como complemento. Rigorosamente, vanto "ir a/para movimento "daqui para lá. Tanto ir a/para movimento "dur" como "vir para/a algum lugar" se constróem com acusativo de movimento porque designam o termo sobre o qual se dirige o movimento.

A indistinção entre o lugar "onde se está" e o lugar "para onde se va1" refle te-se também nos advérbios. Quanto a isto, vejace, absentia (illius) illimabit( $u$ )ri (carta 1, linha 10) Soli nihil poteramus facere, absentia (illius) de lá."

"Sozinhos nada podíamos fazer, havendo de ter a ausencia dele de lá. A forma illim corresponde a illinc "de lá" advérbio que responie" No latim unde "lugar de onde se vem." Seria hinc, "a ausência dele daqui, Romae para clássico, o emprego de formas diferenciadas como Romam, Roma a sobrevivência exprimir circunstâncias de lugar era intrincado; representava a sobrevivencia de um sistema excepcional que tendia a desaparecer. E é exatamente isso que se vê acontecer em latim vulgar.

A propósito do tema que vem sendo desenvolvido, cabe-nos apresentar um Organon, Porto Alegre, $\mathrm{n}^{\circ} 44 / 45$, janeiro-dezembro, 2008, p. 89-102
Varoclum et $G($.)ivan et emi pauca que e $(x)$ pedivi.

"Eu finalmente aqui e ali reuni um pouco de dinheiro e fui a Véroclo e Givan, e comprei umas poucas coisas que enviei".

$I b i$, em latim clássico, é um advérbio de lugar derivado do demonstrativo is, que responde à pergunta $u b i$ ? “onde?", e significa "aí."

$I b i$, nesta ocorrência, não significa "aí", mas é a forma da primeira pessoa do singular do pretérito perfeito do verbo ire "ir" (eo, ii/iui, itum, ire), ou seja, ivi, que o soldado registrou $i b i$, forma que deveria ser falada. Vê-se que o fenômeno da alternância entre /b/e / $/$, que se vê ainda hoje em algumas palavras do português (atualmente diz-se Vasco - nome próprio - e país Basco; em algumas variedades da língua falada, "bassoura" e "barrer", em vez de "vassoura" e "varrer") , ocorria no próprio latim. Cabe lembrar ainda que o verbo eo foi eliminado cedo na língua latina falada, quando passou a se confundir como o pronome pessoal ego, cuja forma vulgar também era eo. As línguas românicas confirmam que eo foi substituído por vado. Além disso, eo era uma forma muito pequena, com pouca perceptibilidade e audibilidade, quase inexpressiva, e tudo que era inexpressivo na língua falada acabou sendo eliminado.

Estamos conscientes que o tratamento pormenorizado da sintaxe das construções de lugar no latim vulgar em comparação com o latim clássico deveria também incluir um estudo detalhado sobre a relação entre os casos e as preposições. É usualmente afirmado que as preposições no latim vulgar passaram a ser usadas com muito mais freqüência porque houve enfraquecimento morfológico dos casos latinos e confusão entre eles na sintaxe. Além disso, como conseqüência do aumento no emprego de preposições, muitas destas passaram a ter maior abrangência semântica, por incorporarem algumas o sentido de outras.

Apenas a título de exemplo, repare-se a seguinte ocorrência da preposição de na carta 2:

(Carta 2, linhas 4-5): Ego te non tanquam amicum habio, set tanqua fratrem gemellum qui de unum ventrem exiut.

A preposição de, que em latim clássico rege ablativo, aqui rege acusativo. A principal razão deste caso ter subsistido enquanto todos os outros foram pouco a pouco sendo eliminados, reside no fato de este ser mais audível, mais perceptível na cadeia sonora. Em muitos nomes e pronomes os outros casos eram realmente pequenos, quase inaudíveis. Esta é a principal razão de as línguas românicas terem o acusativo como o caso lexogênico.

Sabemos que a preposição de encobriu alguns usos de $e x$ e $a b$, na expressão do complemento de procedência, e isso é amplamente comprovado nas línguas românicas, onde somente de subsistiu.

O uso de $d e+$ acusativo, nesta ocorrência, mostra não apenas a mudança de regência da preposição de, mas também, uma ampliação semântica desta. Aqui de engloba a função de ex, que em latim clássico, indica um movimento de Organon, Porto Alegre, $\mathrm{n}^{\circ} 44 / 45$, janeiro-dezembro, 2008, p. 89-102 
de $4^{\mathrm{a}}$ à $2^{\mathrm{a}}$. Quanto aos casos, pouco a pouco foram se desintegrando, reduzindo-se primeiramente a três - nominativo, acusativo e dativo -, depois a dois nominativo e acusativo - e finalmente a um único, o acusativo. Com a "fusão" dos casos, que tradicionalmente se chama "sincretismo", cada vez mais a preposição se fazia necessária para substituir a flexão casual perdida. De fato, muitas formas casuais apresentavam desde a época clássica, o inconveniente de serem totalmente iguais entre si. Assim, o recurso às preposições para a expressão das relações entre as palavras já seria comum em latim vulgar pela maior clareza que davam a frase.

Vimos, através de vários exemplos e detalhamentos de uso das quatro "questões de lugar" em latim clássico, que havia muitas sutilezas semânticas envolvidas no uso dos diversos complementos, que se traduzem no emprego de diversos casos e preposições. No latim vulgar das cartas, principalmente a do soldado tiberiano, pudemos verificar a hesitação no emprego do ablativo e do acusativo, gerada pela queda do $-m$ final do acusativo. Conseqüência desta confusão está na hesitação entre as questões de lugar "onde se está" (ubi) e "para onde se vai" (quo).

\section{Anexos}

A primeira carta é a do soldado tiberiano (CPL, 254), escrita em papiro, do início do século II d.C., encontrada em Karanis, no Egito. A segunda carta é de Rustius Barbarus (CPL 304, CPL 303), também um papiro do século II d.C., encontrados em Ostracon, no Egito ${ }^{1}$.

Entre colchetes [ ] aparecem as restituições de letras ou palavras apagadas; entre parênteses ( ), as soluções de siglas e abreviações.

1a Carta: Carta de um soldado tiberiano, escrita em papiro e encontrada em Karanis; séc.II d.C.; (CPL, 254)

1 ... dico illi, da mi, dico, a(e)s paucum; ibo, dico, ad amicos

2 patris mei. Item acu lentiaminaque mi mandavit; nullum

Os papiros são feitos de um tipo de planta aquática,que tem esse mesmo nome. Durante o Império Romano deveriam existir milhares deles porque eram empregados para registrar tod burocracia do Império, além das correspondências privadas. Como são biodegradáveis, apenas urocracia do lest umas cntenas sobreviveram duas cartas. Como nesta regiăo o grego era usado como língua escrita, há também varios papiros em grego, inclusive um escrito em latim com caracteres gregos (Ver Bassetto, Elementos de filologia românica, p.116 e Herman, Vulgar latin, p.21 (primeiramente publicado em 1967, na coleção "Que sais-je?", sob o título Le latin vulgaire. Paris, Presses Universitaires de France)).

Sabemos que, no latim vulgar, reduz-se o sistema de declinações e de casos.

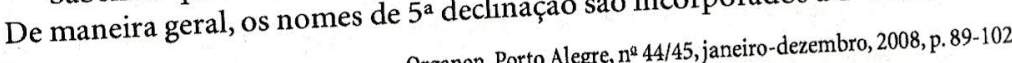

Organon, Porto Alegre, $\mathrm{n}^{\mathrm{a}} 44 / 45$, janeiro-dezembro, 2008, p. 89-102 
3 assem mi dedit. Ego tamen inc ebinde collexi paucum aes ed exica que $\mathrm{e}(\mathrm{x})$ pedivi. ext 5 aequm tempus esset se exiturum Alexandrie s(i)lui(t). Item 6 quam (quam) aureum matri mee in . 7 vestimenta (dedit). Hoc est, inquid, quod pater tus mi .. 8 mandavit. Quo tempus autem veni omnia praefuerunt 9 et (linum)? Matrem meam aute praegnatam inveni. Nil 10 poterat facere. Deinde pos paucos dies parit et non potera 11 mihi succurrere. Item litem abuit Ptolomes pater meu 11 sopera vestimenta mea, et factum est illi venire Alexandrie 13 con tirones et me reliquid con matrem meam. Soli nihil 14 poteramus facere, absentia (illius) illim abit(u)ri. Mater mea 15 (dicit): $\operatorname{Spec}(\mathrm{t})$ emus illum dum venit et ven(i)o tequm 16 Alexandrie et deduco te usque ad nave.Saturninus iam 17 paratus erat exire illa die qu(a)ndo tam magna lites factam 18 est. Dico illi: Veni interpone te si potes aiutare Ptolemaeo

19 patri meo. Non magis quravit me pro xylesphongium sed 19 patri meo. Non et circa res suas. Attonitus exiendo dico illi: 20 sum negotium et circa res suas. Attonitus exiendo méis $21 \mathrm{Da}$ m(i) paucum aes,

22 Alexandrie, im inpendiam. Negabit se habiurum.

23 dicet, Alexandrie et dabo $t(\mathrm{i})$ bi. Ego non abivi. Mater mea

24 no( $n$ haben)s assem, vendidi $(t)$ lentiamina $(\mathrm{u}) \mathrm{t}$ veniam

25 Alexandrie.

digo a ele, dá-me, digo, um pouco de dinheiro; irei, digo, aos amigos de meu pai. Então me me comprei umas poucas coisas e ali reuni un que enviei. Se fizesse tempo favorável, ele nâ disse que in pã para as roupas. Isto é, diz não me deu dinheiro a não ser uma ela, o que o teu pai me mandou. Nesse tempo, porem, tudo teve preferencia tanto a ta como o linho? Encontrei a minha mãe grávida. Nada ela podia fazer. Depois de poucos dias pariu e não podia me auxiliar (socorrer). Também meu pai, Ptolomeu, teve uma briga a respeito de minhas roupas, e aconteceu de ele vir a Alexandria com os recrutas e ma Sozinhos nada podíamos fazer, havendo de ter a ausência chere então, e vou contigo para dele dali. Minha mãe (diz): esperemos ate que ele cho pair naquele dia quando Alexandria e te levo até o navio. Saturnino já estava pronto para sair naquele da quando aconteceu tão grande briga. Digo a ele: vem, interpõe-te, se podes ajudar Ptolomeu, meu pai. Não mais se preocupou comigo, como algo sem importância, mas com seu negócio e suas coisas Saindo atônito digo a ele: dê-me um pouco de dinheiro para as despesas, para que eu possa ir a Alexandria com as minhas coisas. Negou que ele até haveria de ter.Vem, que alexandria e te darei. Eu não fui. Minha mãe, não tendo dinheiro, vendeu os tecidos de linho para que eu viesse a Alexandria.

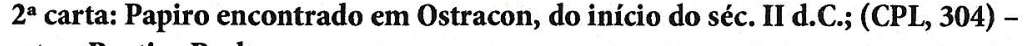
autor: Rustius Barbarus

1 Rustius Barbarus Pompeio fratri suo salutem. Opto deos ut 2 bene valeas que mea vota sunt. Quid mi tan invidiose scribes 3 aut $\tan$ levem me iudicas? Si tan cito virdia mi non mittes, 4 stati amicitiam tuam obliscere debio? Non sum talis aut tan 5 levis. Ego te non tanquam amicum habio, set tanqua fratrem 6 gemellum qui de unum ventrem exiut. Hun(c ver)bum sepius 7 tibi scribo, sed tu (ali)as me iudicas. Accepi fasco coliclos et 8 unum casium. Misi tibe per Arrianum equitem chiloma; entro 9 ha(b)et collyram I et in lintiolo (...) alligatum, quod rogo te ut $10 \mathrm{ema}(\mathrm{s}) \mathrm{mi}$ matium, salem et (mi)ttas mi celerius quia pane 11 volo facere. Vale frater $\mathrm{K}(\mathrm{a})$ rissime

Rustius Barbarus saúda o seu irmão Pompeu. Peço aos deuses que estejas com boa saúde. Estes são os meus votos. Por que razão tão invejosamente me escreves, ou me julgas tão leviano? Se não me mandas depressa as verduras, devo esquecer imediatamente a tua amizade? Não sou tal ou tão leviano. Eu não te tenho como um amigo, mas como um irmão gêmeo, que saiu de um único ventre. Esta palavra te escrevo, mas tu me julgas de outra maneira. Recebi couve num maço e um queijo. Enviei para ti, pelo cavaleiro Arriano, um cesto, dentro há um pão e amarrado num pedacinho de linho $(. . .)^{2}$, que te peço para que me compres uma medida de farinha e sal, e me envies sem demora, porque quero fazer pão. Salve, caríssimo irmão.

\section{Bibliografia}

BASSETTO, Bruno Fregni. Elementos de filologia românica. São Paulo,Edusp, 2001.

BOURCIEZ, Édouard. Éléments de linguistique romane. Paris, Klincksieck, 1967.

CICÉRON, Correspondance. Texte établi et traduit par L.-A, Constans, Tome II. Paris, Les Belles Lettres, 1950.

COUTINHO, Ismael de Lima. Pontos de gramática histórica. Rio de Janeiro, Acadêmica, 1973.

DIAZ Y DIAZ, Manuel. Antología del latín vulgar. Madrid, Gredos, 1962.

${ }^{2}$ (...) falta a palavra, talvez seja "moedas", pelo que se tem na seqüência.

Organon, Porto Alegre, $\mathrm{n}^{\circ}$ 44/45, janeiro-dezembro, 2008, p. 89-102 
ERNOUT-THOMAS. Syntaxe latine. Paris, Klincksieck, 1953. HAADSMA, R.A. \& NUCHELMANS, J. Précis de latin vulgaire. Groningen, J.B. Wolters, 1963.

HERMAN, József. Vulgar latin. Philadelphia, Penn State Press, 1999. (Editado primeiramente em 1967, sob o título Le latin vulgaire,. Paris, Presses Universitaires de France).

MAROUZEAU, Jules. Traité de stylistique latine. Paris, Les Belles Lettres, 1946.

.Quelques aspects de la formation du latin littéraire. Paris, Klincksieck, 1949.

MAURER Jr., Theodoro Henrique. A unidade da România ocidental. USP/ FFLCH, 1951.

.Gramática do latim vulgar. Rio de Janeiro, Acadêmica, 1959.

.O problema do latim vulgar. Rio de Janeiro, Acadêmica, 1962.

MEILLET, Antoine Esquisse d'une histoire de la langue latine. Paris, Klincksieck, 1933.

RIEMANN, O. Syntaxe latine. Paris, Klincksieck, 1927.

VÄÄNÄNEN, Veikko Le latin vulgaire des inscriptions ompéiennes. Helsinki, Annales Academiae Scientiarum Fennicae, 1937.

.Latin, langue parlée et langue écrite: réactions et régressions. Linguistique et Philologie Romanes: Actes du Xe Congrès International de Linguistique et Philologie Romanes, Strasbourg, 23-28 avril 1962. Paris, Klincksieck, 1965.

.Introduction au latin vulgaire. Paris, Klincksieck, 1981. 